\title{
EXTREME-ENVIRONMENT HETEROSIS AND GENETIC LOADS
}

\author{
P. A. PARSONS \\ Department of Genetics and Human Variation, La Trobe University, Victoria, Australia
}

Received 7.xii.70

IN the classic population cage experiments of Wright and Dobzhansky (1946) and Dobzhansky (1948a) in D. pseudoobscura, large fitness differentials between hetero- and homokaryotypes leading to heterokaryotype advantage and stable polymorphisms were found at $25^{\circ} \mathrm{C}$. but not at $16 \frac{1}{2}^{\circ} \mathrm{C}$. with an intermediate situation at $22^{\circ} \mathrm{C}$. (van Valen, Levine and Beardmore, 1962). For $D$. pseudoobscura, $25^{\circ}$ C. represents a more extreme environment than $16 \frac{1}{2}^{\circ} \mathrm{C}$. Other examples of heterokaryotype advantage in extreme environments have been reported, e.g. for cold tolerance (Heuts, 1948) and mating speed and duration of copulation at high temperatures (Parsons and Kaul, 1966). Probably the best example is that of Thomson (1964; and see also Parsons and McKenzie, 1971) for desiccation. Thus it can be argued that heterokaryotype advantage is minimal in optimal environments and much more pronounced in extreme environments. Assuming this to be a general phenomenon, it provides a further explanation, additional to those presented in the literature, for the high level of genetic polymorphism in natural populations without an excessive genetic load (see Grow and Kimura, 1970, for a general discussion of genetic loads). Thus under more optimal environments the species might have a high level of polymorphism with little concomitant genetic load, but in times of environmental stress, heterozygote advantage would be more pronounced for some polymorphisms according to the stress. Hence, only a minor part of the population in the wild would then exhibit a high level of heterozygote advantage with its concomitant genetic load.

Analogous are the observations of the enhancement of heterosis for hybrids between inbred lines under extreme environments such as high temperatures [e.g. larval survival (Parsons, 1959) and longevity (Parsons, 1966 ) in D. melanogaster and growth rates in Arabidopsis thaliana (Langridge, 1962) and maize (McWilliam and Griffing, 1965)] and low temperatures [viability in $D$. melanogaster (Fontdevila, 1970) and growth rates in maize (McWilliam and Griffing, 1965)]. A further very good example in plants comes from Bucio Alanis, Perkins and Jinks (1969) in Nicotiana rustica, where over a series of environments the magnitude of heterosis for crosses between inbred strains was found to fall off as the environment improves. Based on detailed biometrical considerations, they showed that the change in heterosis can be predicted from the relative sensitivities of hybrid and inbred lines to changes in the environment. This seems an approach worth developing further. Comparing homozygotes for chromosome II of $D$. pseudoobscura with the corresponding heterozygotes gives similar results for viability at high temperatures (Dobzhansky et al., 1955) and for cold temperature resistance (Marinkovic, Crumpacker and Salceda, 1969). For preadult survival for chromosome II of D. melanogaster at $29^{\circ} \mathrm{C}$. (Tobari, 1966) the same result has been found. In mice, heterosis in hybrids between two inbred strains for various measures of fitness has been shown to be enhanced in cold environments (Barnett and Mount, 1967). It could be expected that mice being endotherms would not show heterosis in extreme environ- 
ments like insects and plants, but although the results need to be generalised, this does not seem to be so. The above examples are not from natural populations, but they are analogous in that in an outbred species, homozygotes and heterozygotes are being compared and show that the genetic load, in this case the inbreeding load, is higher in adverse environments than in favourable ones.

Langridge (1962, 1968) has proposed an explanation of temperaturedependent heterosis at the molecular level, such that heat-sensitive enzymes are the most common consequences of mutations that do not inactivate the enzyme, and that some of these mutations are expressed in the organism only at high temperatures and that complete dominance of the normal phenotype is expected in a heterozygote. Support for his hypothesis has come from mutations affecting the structural gene for $\beta$-galactosidase in Escherichia coli $\mathrm{Kl} 2$ (Langridge, 1968). In agreement is a recent report of Gibson and Miklovich (1970) on alcohol dehydrogenase in D. melanogaster, which shows in some cases that enzyme activity is significantly heterotic after incubation of homogenates for 10 minutes at $40^{\circ} \mathrm{C}$., compared with prior incubation at $25^{\circ} \mathrm{C}$. Assuming a easonably high correlation between mortality due to desiccation and high temperature stress as found in $D$. melanogaster (Parsons, 1970), this explanation could apply to both stresses. Low temperature sensitive enzymes seem rarer (Langridge, 1968) and so heterosis might be expected to be less extreme, although it does occur as pointed out. The low temperature heterosis in maize observed by McWilliam and Griffing (1965) can be explained by the presence of mutant genes in the homozygotes restricting the full formation of chlorophyll. It seems difficult to postulate anything specific apart from low-temperature sensitive enzymes to explain the low temperature heterosis in Drosophila, because of the multiplicity of physiological possibilities that occur (Clarke, 1967).

The likely alternative hypothesis comes from evidence for the co-adaptation or the relational balance of gene complexes between chromosomes in heterozygotes, which is broken down in homozygotes (see Mather, 1943; Lee and Parsons, 1968, for references). Because heterozygotes are the genotypes most commonly exposed to natural selection in outbred species, the general observation that they are less variable in a multiplicity of environments is then not unexpected, and as a concomitant of this is the increased level of heterosis found in stress environments. Needless to say, these two hypotheses are not mutually exclusive, and the latter could be put in molecular terms. Even if the molecular hypothesis is too restrictive, in Drosophila it is quite likely that the major environmental stresses that a wild population is likely to be subjected to, will be tied up with variations in temperature and humidity. It seems therefore better to talk of extremeenvironment heterosis, which would encompass all stresses, and would admit the great importance of temperature (and humidity) in this regard. Furthermore, the molecular hypothesis seems more difficult to apply to endotherms than ectotherms because of the importance of temperatureregulatory mechanisms in endotherms. For this reason it may well be that the relative importance of the two hypotheses may vary between these two categories of organisms, although evidence has been presented for extremeenvironment heterosis in both.

The molecular explanation of extreme-environment heterosis will no doubt be tested in the next few years as a result of the recent spectacular 
increase in work devoted to analysing individuals of several species for enzyme variants by means of starch gel electrophoresis (see Lewontin and Hubby, 1966; Stone, Kojima and Johnson, 1969). So far there is little evidence for overdominance for enzyme polymorphisms, except for a brief report by Powell and Richmond (1971) in D. paulistorum for a sex-linked enzyme locus controlling tetrazolium oxidase. In any case, assuming the generality of environment-dependent heterosis, overdominance would not be expected to be common, since most experiments would have been carried out in non-extreme environments. On the other hand, frequency-dependent selection has been shown to be responsible for the maintenance of biochemical polymorphism in at least one system, Est-6 in D. melanogaster (Kojima and Yarbrough, 1967).

Examples of the dependence of enzyme polymorphisms on the environment (and see also Parsons and McKenzie, 1971) comes from a cline in $D$. ananassae for the major allele in the Est-C system in the Pacific such that its frequency increases from north to south towards the equator and then south of the equator it decreases (Stone, Kojima and Johnson, 1969), suggesting a partial association with temperature, and from a possible association with environment in particular the weather in the harvester ant, Pogonomyrex barbatus in Texas (Johnson et al., 1969). In laboratory populations of $D$. melanogaster, Beardmore $(1970)$ has shown that the frequency of the esterase- $6^{F}$ allele tends to be at higher frequencies in populations at high temperatures. Prakash and Lewontin (1968) have shown considerable divergence between inversions of $D$. pseudoobscura for enzyme and protein variants, which seem to date from the origin of the inversions predating the present distribution of the species. There is therefore the possibility that loci controlling these variants may be of importance in explaining the wellknown associations of inversions in this species with season, altitude and environmental factors (see, for example, Dobzhansky, 1947, 1948b), and the likelihood of this is enhanced if we accept, either partly or wholly, a molecular basis for environment-dependent heterosis.

\section{SUMMARY}

1. In D. pseudoobscura, heterokaryotype advantage is more pronounced in extreme than in optimal environments. Similarly, hybrids between inbred lines and other homozygotes tend to show an enhancement of heterosis in extreme environments in several species of animals and plants.

2. Such extreme-environment heterosis may be associated with temperature sensitive and correlated enzymes, or the general poorer fitness of homozygotes compared with the corresponding heterozygotes because of the breakdown of relational balance in the heterozygotes in forming homozygotes. The two hypotheses are probably not mutually exclusive, and may differ in importance in different groups of organisms.

3. Extreme-environment heterosis provides one explanation of the high level of polymorphisms present in natural populations additional to those already advanced in the literature, since it would not imply a high genetic load under relatively optimal environments.

4. Certain polymorphic enzyme systems show a dependence on the environment in the wild, and it is suggested that loci controlling enzyme and protein variants associated with different inversions in species such as 
D. pseudoobscura may be of importance in explaining the associations of such inversions with season, altitude and other environmental factors.

Acknowledgements.-I am grateful to Professor J. L. Jinks, F.R.S., for helpful comments. This work was supported by a grant from the Australian Research Grants Committee.

\section{REFERENCES}

BARnETt, s. A., AND mOUnT, L. E. 1967. Resistance to cold in mammals. Thermobiology (Ed. A. H. Rose), 411-477. Academic Press.

BEARDMORE, J. A. 1970. Ecological factors and the variability of genepools in Drosophila. In Essays in Evolution and Genetics in Honor of Theodosius Dobzhansky (Eds. M. K. Hecht and W. C. Steere), New York, Appleton-Century-Crofts, pp. 299-314.

BUCIO ALANIS, L., PERKINS, J. M., AND JINKS, J. L. 1969. Environmental and genotypeenvironmental components of variability. V. Segregating generations. Heredity, 24, 115-127.

ClARKe, K. U. 1967. Insects and temperature. Thermobiology (Ed. A. H. Rose), 293-352. Academic Press.

crow, J. F., AND KImUra, M. 1970. An Introduction to Population Genetics Theory. Harper \& Row, New York.

DOBZHANSKY, TH. 1947. Adaptive changes induced by natural selection in wild populations of Drosophila. Evolution, 1, 1-16.

DOBZHANSKy, тH. 1948a. Genetics of natural populations. XVIII. Experiments on chromosomes of Drosophila pseudoobscura from different geographic regions. Genetics, 33, 588-602.

DOBZHANSKY, TH. 1948b. Genetics of natural populations. XVI. Altitudinal and seasonal changes produced by natural selection in certain populations of Drosophila pseudoobscura and Drosophila persimilis. Genetics, 33, 158-176.

DOBZHANSKy, TH., PAVlovsky, O., SPASSKy, B., AND SPASSKy, N. 1955. Genetics of natural populations. XXIII. Biological role of deleterious recessives in populations of Drosophila pseudoobscura. Genetics, 40, 781-796.

FONTDEVILA, A. 1970. Genotype-temperature interaction in Drosophila melanogaster. I. Viability. Genetica, 41, 257-264.

GIBSON, J. B., AND MIKLOVICH, R. 1970. Modes of variation in alcohol dehydrogenase in Drosophila melanogaster. Experientia (in press).

HEUTS, м. J. 1948. Adaptive properties of carriers of certain gene arrangements in Drosophila pseudoobscura. Heredity, 2, 63-75.

JOHNSON, F. M., SCHAFFER, H. E., GILLASPY, J. E., AND ROCKWOOD, E. s. 1969. IsOzyme genotype-environment relationships in natural populations of the harvester ant Pogonomyrex barbatus, from Texas. Biochemical Genetics, 3, 429-450.

xojIMA, K-I., AND YARBrough, к. м. 1967. Frequency-dependent selection at the esterase locus in Drosophila melanogaster. Proc. Natl. Acad. Sci., U.S., 57, 645-649.

LANGRIDGE, J. 1962. A genetic and molecular basis for heterosis in Arabidopsis and Drosophila. Amer. Naturalist, 96, 5-27.

LANGRIDGE, J. 1968. Thermal responses of mutant enzymes and temperature limits to growth. Molec. Gen. Gdnetics, 103, 116-126.

LEE, B. T. O., AND PARSONS, P. A. 1968. Selection, prediction and response. Biological Reviews, 43, 139-174.

LEWONTIN, R. G., AND HUBBY, J. L. 1966. A molecular approach to the study of genic heterozygosity in natural populations. II. Amount of variation and degree of heterozygosity in natural populations of Drosophila pseudoobscura. Genetics, 54, 595-609.

MCWIlliam, J. R., AND GRIFFING, B. 1965. Temperature-dependent heterosis in maize. Aust. 7. Biol. Sci., 18, 569-583.

MARINKOvic, D., GRUMPACKER, D. W., AND SAlCEDA, v. M. 1969. Genetic loads and cold temperature resistance in Drosophila pseudoobscura. Amer. Naturalist, 103, 235-246.

mather, K. 1943. Polygenic inheritance and natural selection. Biological Reviews, 18, $32-64$.

PARSONs, P. A. 1959. Genotype-environmental interactions for various temperatures in Drosophila melanogaster. Genetics, 44, 1325-1333. 
PARSONS, P. A. 1966. The genotypic control of longevity in Drosophila melanogaster under two environmental regimes. Aust. 7. Biol. Sci., 19, 587-591.

PARsons, P. A. 1970. Genetic heterogeneity in natural populations of Drosophila melanogaster for ability to withstand desiccation. Theoret. and Appl. Genetics, 40, 261-266.

PARsons, P. A., AND KAUl, D. 1966. Mating speed and duration of copulation in Drosophila pseudoobscura. Heredity, 21, 219-225.

PARSONS, P. A., AND maKenZIE, J. A. 1971. The ecological genetics of Drosophila. Evolutionary Biology (in press).

POWELL, J. R., AND RICHMOND, R. C. 1971. Evidence of heterosis associated with an enzyme locus in a natural population of Drosophila. Genetics, (in press).

PRAKASH, s., AND LEWONTIN, R. G. 1968. A molecular approach to the study of genic heterozygosity in natural populations. III. Direct evidence of coadaptation in gene arrangements of Drosophila. Proc. Natl. Acad. Sci. U.S., 59, 398-405.

STONE, w. s., KOJIMA, K-I., AND JOHnson, F. M. 1969. Enzyme polymorphisms in animal populations. Japan 7 . Genetics, 44, Suppl. 1, 166-171.

тномson, J. A. 1964. An experimental study of the influence of environmental factors on population structure in Drosophila pseudoobscura. Forlowa. Ph.D. Thesis, University of Melbourne.

TOBARI, I. 1966. Effects of temperature on the viabilities of homozygotes and heterozygotes for second chromosomes of Drosophila melanogaster. Genetics, 54, 783-791.

VAN VALEN, L., LEVINE, L., AND BEARDMORE, J. A. 1962. Temperature sensitivity of chromosomal polymorphism in Drosophila pseudoobscura. Genetica, 33, 113-127.

WRIGHT, s., AND DOBZHANSKy, TH. 1946. Genetics of natural populations. XII. Experimental reproduction of some of the changes caused by natural selection in certain populations of Drosophila pseudoobscura. Genetics, 31, 125-156.

\title{
THE EFFECT OF UNEQUAL MATING FREQUENCIES ON THE VARIANCE EFFECTIVE NUMBER IN RANDOM MATING POPULATIONS
}

\author{
P. STAM \\ Department of Genetics of the Agricultural University, Wageningen, The Netherlands
}

Received 21.xii.70

THE effective number in a random mating population can be described as " inbreeding effective number" or, alternatively, as "variance effective number" (Crow, 1954; Grow and Kimura, 1970). The latter, $\mathcal{N} e(v)$, is defined by the variance of gene frequency change $(\Delta q)$ per generation:

where $p=1-q$.

$$
\operatorname{var}(\Delta q)=\frac{p q}{2 \mathcal{N} e(v)}
$$

Following Grow (1954), we have

$$
\operatorname{var}(\Delta q)=\frac{p q}{4 \mathcal{N}}\left(1+\frac{\operatorname{var}(k)}{\varepsilon(k)}\right)
$$

in which $\mathcal{N}$ is the actual population number and $k$ is the number of effective gametes contributed by a single individual. When $k$ is Poisson-distributed, $\operatorname{var}(k) / \varepsilon(k)$ equals unity and (2) reduces to the expression in the binomial sampling model:

$$
\operatorname{var}(\Delta q)=\frac{p q}{2 \mathcal{N}}
$$

so that $\mathcal{N} e(v)=\mathcal{N}$.

Now, individual variation in number of matings, whether or not in- 